\title{
On the relationship between auditory-evoked potential and subjective preference for sound field
}

\author{
Yoichi Ando, ${ }^{*}, * *$ Seong-Hoon Kang, ${ }^{*}$ and Koji Morita** \\ * Graduate School of Science and Technology, Kobe University, \\ 1-1, Rokkodai, Nada, Kobe, 657 Japan \\ **Faculty of Engineering, Kobe University, \\ 1-1, Rokkodai, Nada, Kobe, 657 Japan
}

(Received 6 April 1987)

\begin{abstract}
The auditory evoked potential (AEP) and the subjective preference for sound field were investigated as a function of the time delay $\left(\Delta t_{1}\right)$ of sound field with single reflection. The stimulus was a female voice with $0.9 \mathrm{~s}$ duration and the delay was adjusted in a range of 0 to $125 \mathrm{~ms}$. The information related to subjective preference appeared in the latency components, in which a relatively long-latency responses was observed at the most preferred delay. It is shown that the difference of latencies of AEPs over both hemispheres in response to a pair of sound fields with different delay contains almost the same information that is expressed by the subjective preference value obtained from paired comparison tests.
\end{abstract}

PACS number: 43. 63. Rf, 43. 66. $\mathrm{Pn}$, 43. 55. $\mathrm{Br}$

\section{INTRODUCTION}

The sound-field parameters in a room which independently influence subjective preference can be reduced to the following four: (1) initial delay time $\left(\Delta t_{1}\right),(2)$ level of listening, (3) reverberation time, and (4) magnitude of interaural crosscorrelation (IACC). ${ }^{1-6)}$ In results of subjective preference tests, the preferred delay of single reflection can be determined by the effective duration $\left(\tau_{\mathrm{e}}\right)$ of autocorrelation function (ACF) and the amplitude of single reflection. ${ }^{3)}$ In psychological assessments, tone coloration or image shift effect occurs for a very short delay range $\left(\Delta t_{1} \rightarrow 0 \mathrm{~ms}\right)$, and if $\Delta t_{1}$ is longer than $\tau_{e}$, echo disturbance effect is perceived. Subjective preference judgment of sound field with single reflection agreed well even among subjects of different nationality. ${ }^{7)}$

The purpose of this study is to examine a parallel relation between auditory-evoked potential (AEP) and subjective preference response to sound field with single reflection. In order to know the effects of delay time on the evoked potentials and different hemispheric processing of delayed sound perception, AEP in response to changes of the delay were recorded from both temporal areas. Then, paired comparison tests for sound field with single reflection were carried out by adjusting the delay time with the same subjects as for AEP recording.

\section{SOURCE SIGNAL AND SUBJECTS}

\subsection{Source Signal}

The property of the source signal $p(t)$ in a sound field may significantly be represented by its autocorrelation function $\Phi_{\mathrm{p}}(\tau)$ which is given by

$$
\Phi_{\mathrm{p}}(\tau)=\lim _{T \rightarrow \infty} \frac{1}{2 T} \int_{-T}^{+T} p^{\prime}(t) p^{\prime}(t+\tau) d t
$$

where $p^{\prime}(t)=p(t) * a(t), a(t)$ corresponding to the ear sensitivity characterized by the external ear and the middle ear. ${ }^{1)}$ For convenience, $a(t)$ is chosen as the impulse response of an A-weighting filter. The above equation may be divided into the average intensity of 


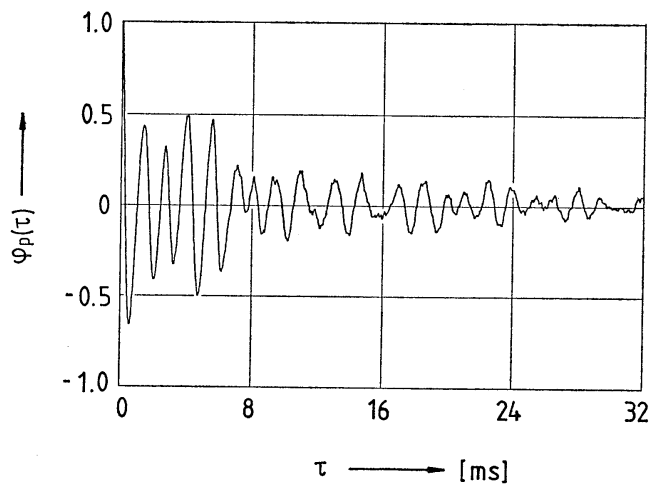

Fig. 1 Measured autocorrelation function of the source speech signal used.

the sound signal $\Phi_{\mathrm{p}}(0)$ and the normalized autocorrelation function which is defined by

$$
\phi_{\mathrm{p}}(\tau)=\Phi_{\mathrm{p}}(\tau) / \Phi_{\mathrm{p}}(0) .
$$

The effective duration of ACF is defined by the delay $\tau_{\mathrm{e}}$ such that the envelope of the normalized ACF becomes 0.1 after the delay. ${ }^{3)}$ The speech signal used in both AEP recording and preference judgment was a female voice (ZOUKI-BAYASHI: meaning "coppice" in Japanese) of $0.9 \mathrm{~s}$ duration recorded in an anechoic chamber. The autocorrelation function measured with an A-weighting filter is shown in Fig. 1. The effective duration $\left(\tau_{\mathrm{e}}\right)$ of the function may be found to be about $25 \mathrm{~ms}$.

\subsection{Subjects}

The subjects chosen for this study were eight male students with normal hearing. The mean age of the subjects was 21 years, ranging from 18 to 23 . They were not paid for their participation. All the subjects were right-handed as determined by a questionnaire $^{8)}$ and also considered themselves right-handed.

\section{AUDITORY-EVOKED POTENTIAL IN RESPONSE TO SOUND FIELD WITH SINGLE REFLECTION}

\subsection{Procedure}

The subject was comfortably seated, in a chair in front of loudspeakers in a soundproof chamber. They were instructed to keep their eyes closed and to pay attention to the sound without any head movement.

Two loudspeakers, which produce direct frontal sound (horizontal angle $\xi=0^{\circ}$, elevation angle $\eta=0^{\circ}$ ) with single reflection $\left(\xi=0^{\circ}\right.$ and $\left.\eta=7^{\circ}\right)$, were arranged in the soundproof chamber. The delay time $\Delta t_{1}$ of single reflection was adjusted in a range of 0 to $125 \mathrm{~ms}$ (5 different delays: 0, 5, 25, 75 and 125 ms). For simplicity, the amplitude of reflection $A_{1}$ was adjusted to be the same as that of direct sound, i.e., $A_{1}=1.0$. A pair of sound fields, which consisted of the reference stimulus $\left(\Delta t_{1}=0 \mathrm{~ms}\right)$ and the test stimuli $\left(\Delta t_{1}=0,5,25,75\right.$, or $\left.125 \mathrm{~ms}\right)$, were reproduced at a constant interstimulus interval of $1 \mathrm{~s}$, similar to the preference tests performed later as described below. The subjects were not asked their subjective impressions of the two different sound fields in the recording of AEPs.

The sound without delay as a reference stimulus $\left(\Delta t_{1}=0 \mathrm{~ms}\right)$ was first presented, and then the test stimulus was presented. These alternating stimuli were repeated 50 times in a session. The total pressure level of the two sounds was held constant at a peak value of $70 \mathrm{~dB}(\mathrm{~A})$. For each subject, the test was conducted two times within one week and the recorded AEP results of the two tests were averaged. The subjects were asked to abstain from smoking and drinking of any kind of alcoholic beverage for about $12 \mathrm{~h}$ before being tested.

\subsection{Recording of AEPs}

Unipolar evoked-potential recording was made from the left and right temporal areas labelled as $T_{3}$ and $T_{4}$, respectively, according to the International $10 \sim 20$ system. $^{9)} \quad$ The reference electrodes were located on the right and left earlobes and connected together. The ground electrode was placed at the center of the forehead. Silver electrodes $(7-\mathrm{mm}$ diameter) with electrolytic paste were used.

The electrical signals were amplified using a polygraph (Nihon Kohden, Type 7109) with a bandwidth of 0.3 to $60 \mathrm{~Hz}$. Fifty responses were averaged online with a signal averager (Nihon Kohden, Type ATAC-450). The leading edge of each sound signal was used as the trigger signal for the signal averager. The sweep interval was $512 \mathrm{~ms}$ after stimulus onset and the data sampled at $2 \mathrm{~ms}$ intervals were stored in the signal averager. The two channels of data from $T_{3}$ and $T_{4}$ were averaged simultaneously, and the data on two stimulus conditions $\left(\Delta t_{1}=0 \mathrm{~ms}\right.$ for reference and the controlled $\Delta t_{1}$ being $5,25,75$, or $125 \mathrm{~ms}$ ) were averaged independently. The amplitudes were calibrated using a $50 \mu \mathrm{V}$ calibration signal with an EEG amplifier. The averaged AEPs 


\section{Y. ANDO et al.: AUDITORY-EVOKED POTENTIAL AND PREFERENCE}

were recorded on an X-Y plotter.

\subsection{Results}

Figure 2 shows the AEPs obtained from one subject in a session. Five peaks of AEPs can readily be identified in each response. Eight measures, consisting of three amplitude scores and five latency scores, were used as indicators of electrophysiological responses. The peak-to-peak amplitude scores were measured in $\mu \mathrm{V}$ at the point where the voltage was maximally positive and negative. Thus, three amplitude scores were obtained for the difference between $\mathbf{P}_{1}$ and $\mathrm{N}_{1}\left[A\left(\mathbf{P}_{1}-\mathrm{N}_{1}\right)\right], \mathbf{N}_{1}$ and $\mathbf{P}_{2}\left[A\left(\mathrm{~N}_{1}-\mathbf{P}_{2}\right)\right]$, and $\mathrm{P}_{2}$ and $\mathrm{N}_{2}\left[A\left(\mathrm{P}_{2}-\mathrm{N}_{2}\right)\right]$, and the latency scores were the time interval between the stimulus onset and the peaks of $P_{1}, N_{1}, P_{2}, N_{2}$ and $P_{3}$ for the test stimuli. The scores for the reference stimulus were defined by $A\left(\mathrm{P}_{1}{ }^{\prime}-\mathrm{N}_{1}{ }^{\prime}\right), A\left(\mathrm{~N}_{1}{ }^{\prime}-\mathrm{P}_{2}{ }^{\prime}\right)$, and $A\left(\mathrm{P}_{2}{ }^{\prime}-\mathrm{N}_{2}{ }^{\prime}\right)$ for the amplitude, and $\mathrm{P}_{1}{ }^{\prime}, \mathrm{N}_{1}{ }^{\prime}, \mathrm{P}_{2}{ }^{\prime}, \mathrm{N}_{2}{ }^{\prime}$, and $\mathrm{P}_{3}{ }^{\prime}$ for the latency.

Tables 1 and 2 show the amplitudes and their standard deviations from the left and right hemispheres for the eight subjects, for the test sound fields (a)

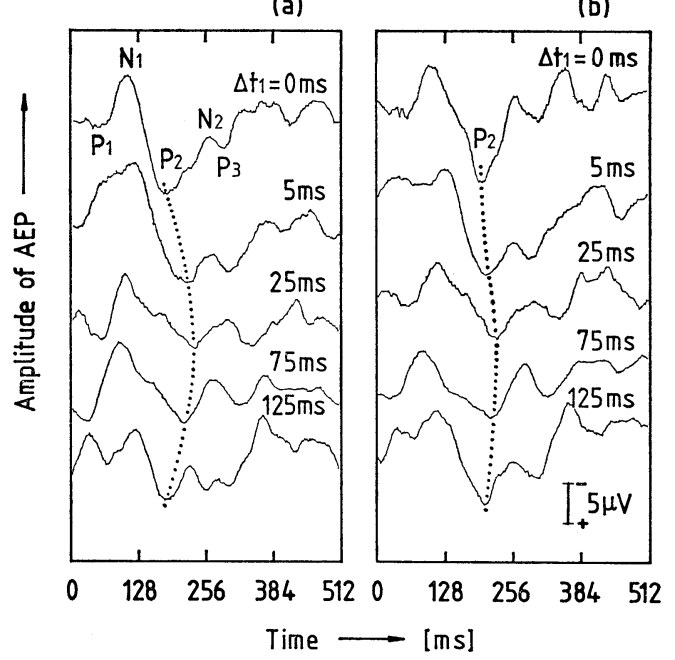

Fig. 2 AEPs elicited by speech signal recorded for a single subject. Dotted curves are the loci of $\mathbf{P}_{2}$ latency against $\Delta t_{1}$. Maximum latencies appeared at $\Delta t_{1}=25$ ms. (a) Left hemisphere, (b) Right hemisphere.

Table 1 Mean amplitudes of AEP for the eight subjects, in microvolts, as a function of delay time $\Delta t_{1}$ of the test sound. Values in brackets show standard deviation.

\begin{tabular}{|c|c|c|c|c|c|c|c|c|c|c|}
\hline \multirow{3}{*}{ Amplitude } & \multicolumn{5}{|c|}{ Left hemisphere } & \multicolumn{5}{|c|}{ Right hemisphere } \\
\hline & \multicolumn{5}{|c|}{ Delay time, $\Delta t_{1}[\mathrm{~ms}]$} & \multicolumn{5}{|c|}{ Delay time, $\Delta t_{1}[\mathrm{~ms}]$} \\
\hline & 0 & 5 & 25 & & 125 & 0 & & & & 120 \\
\hline$A\left(\mathrm{P}_{1}-\mathrm{N}_{1}\right)$ & $\begin{array}{c}6.6 \\
(1.6)\end{array}$ & $\begin{array}{l}5.4 \\
(1.7)\end{array}$ & $\begin{array}{c}5.8 \\
(1.3)\end{array}$ & $\begin{array}{c}5.3 \\
(1.9)\end{array}$ & $\begin{array}{c}5.5 \\
(1.7)\end{array}$ & $\begin{array}{l}5.7 \\
(1.5)\end{array}$ & $\begin{array}{l}4.2 \\
(1.3)\end{array}$ & $\begin{array}{c}5.1 \\
(1.2)\end{array}$ & $\begin{array}{l}3.9 \\
(1.2)\end{array}$ & $\begin{array}{l}4.3 \\
(1.0)\end{array}$ \\
\hline$A\left(\mathrm{~N}_{1}-\mathrm{P}_{2}\right)$ & $\begin{array}{c}8.8 \\
(2.5)\end{array}$ & $\begin{array}{l}7.4 \\
(1.9)\end{array}$ & $\begin{array}{c}7.7 \\
(1.9)\end{array}$ & $\begin{array}{c}7.3 \\
(1.7)\end{array}$ & $\begin{array}{c}7.8 \\
(1.8)\end{array}$ & $\begin{array}{l}8.6 \\
(2.8)\end{array}$ & $\begin{array}{l}7.2 \\
(2.3)\end{array}$ & $\begin{array}{l}7.5 \\
(2.2)\end{array}$ & $\begin{array}{l}6.9 \\
(1.7)\end{array}$ & $\begin{array}{l}6.6 \\
(1.9)\end{array}$ \\
\hline$A\left(\mathrm{P}_{2}-\mathrm{N}_{2}\right)$ & $\begin{array}{c}5.0 \\
(1.5)\end{array}$ & $\begin{array}{c}3.9 \\
(1.1)\end{array}$ & $\begin{array}{c}5.2 \\
(1.6)\end{array}$ & $\begin{array}{c}3.5 \\
(0.7)\end{array}$ & $\begin{array}{c}3.8 \\
(0.5)\end{array}$ & $\begin{array}{c}5.1 \\
(1.9)\end{array}$ & $\begin{array}{c}3.9 \\
(1.4)\end{array}$ & $\begin{array}{l}4.4 \\
(1.4)\end{array}$ & $\begin{array}{c}3.9 \\
(1.1)\end{array}$ & $\begin{array}{c}3.6 \\
(0.7)\end{array}$ \\
\hline
\end{tabular}

Table 2 Mean amplitudes of AEP for the eight subjects, in microvolts, as a function of delay time $\Delta t_{1}$ of the test sound for the reference sound with $\Delta t_{1}=0 \mathrm{~ms}$. Values in brackets show standard deviation.

\begin{tabular}{|c|c|c|c|c|c|c|c|c|c|c|}
\hline \multirow{3}{*}{ Amplitude } & \multicolumn{5}{|c|}{ Left hemisphere } & \multicolumn{5}{|c|}{ Right hemisphere } \\
\hline & \multicolumn{5}{|c|}{ Delay time, $\Delta t_{1}[\mathrm{~ms}]$} & \multicolumn{5}{|c|}{ Delay time, $\Delta t_{1}[\mathrm{~ms}]$} \\
\hline & 0 & 5 & 25 & 75 & 125 & 0 & & 25 & 75 & 125 \\
\hline$A\left(\mathrm{P}_{1}^{\prime}-\mathrm{N}_{1}^{\prime}\right)$ & $\begin{array}{c}6.6 \\
(1.6)\end{array}$ & $\begin{array}{c}5.8 \\
(0.6)\end{array}$ & $\begin{array}{c}6.1 \\
(1.3)\end{array}$ & $\begin{array}{l}6.6 \\
(1.8)\end{array}$ & $\begin{array}{l}6.1 \\
(1.7)\end{array}$ & $\begin{array}{l}5.7 \\
(1.5)\end{array}$ & $\begin{array}{l}5.3 \\
(0.7)\end{array}$ & $\begin{array}{c}5.9 \\
(1.8)\end{array}$ & $\begin{array}{c}5.6 \\
(1.0)\end{array}$ & $\begin{array}{c}5.9 \\
(1.3)\end{array}$ \\
\hline$A\left(\mathrm{~N}_{1}^{\prime}-\mathrm{P}_{2}^{\prime}\right)$ & $\begin{array}{l}8.8 \\
(2.5)\end{array}$ & $\begin{array}{l}9.1 \\
(1.6)\end{array}$ & $\begin{array}{c}8.9 \\
(2.2)\end{array}$ & $\begin{array}{l}9.2 \\
(1.9)\end{array}$ & $\begin{array}{c}7.9 \\
(1.9)\end{array}$ & $\begin{array}{c}8.6 \\
(2.8)\end{array}$ & $\begin{array}{l}9.0 \\
(2.1)\end{array}$ & $\begin{array}{l}8.3 \\
(1.7)\end{array}$ & $\begin{array}{l}7.7 \\
(2.1)\end{array}$ & $\begin{array}{c}6.5 \\
(1.3)\end{array}$ \\
\hline$A\left(\mathrm{P}_{2}{ }^{\prime}-\mathrm{N}_{2}{ }^{\prime}\right)$ & $\begin{array}{c}5.0 \\
(1.5)\end{array}$ & $\begin{array}{c}4.4 \\
(0.9)\end{array}$ & $\begin{array}{l}4.9 \\
(1.3)\end{array}$ & $\begin{array}{c}5.4 \\
(0.6)\end{array}$ & $\begin{array}{c}4.8 \\
(0.8)\end{array}$ & $\begin{array}{l}5.1 \\
(1.9)\end{array}$ & $\begin{array}{c}4.9 \\
(0.9)\end{array}$ & $\begin{array}{l}4.8 \\
(1.6)\end{array}$ & $\begin{array}{l}4.4 \\
(0.9)\end{array}$ & $\begin{array}{c}4.5 \\
(1.2)\end{array}$ \\
\hline
\end{tabular}




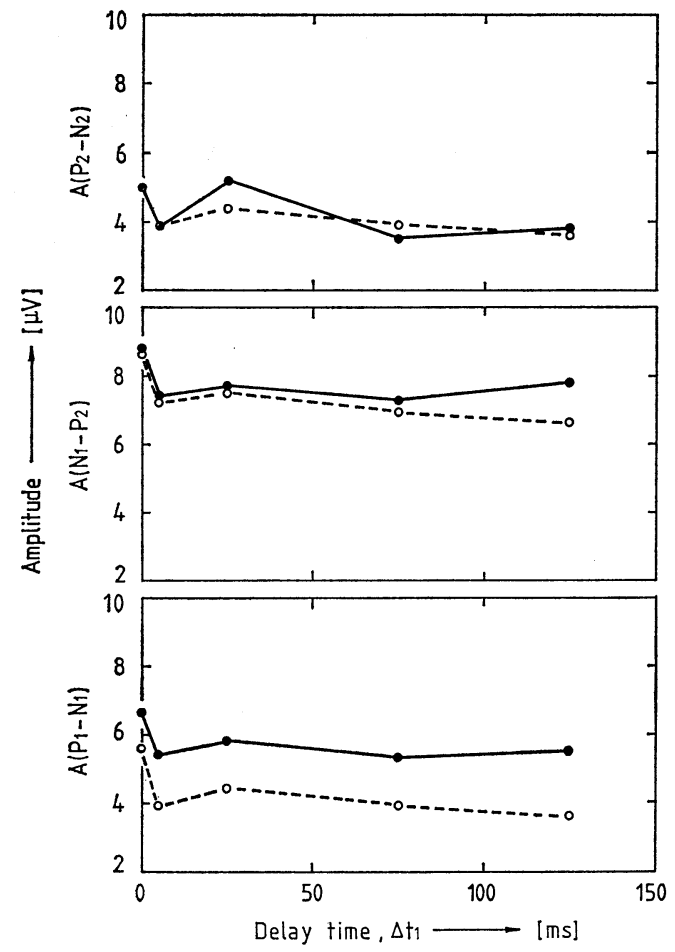

(a)

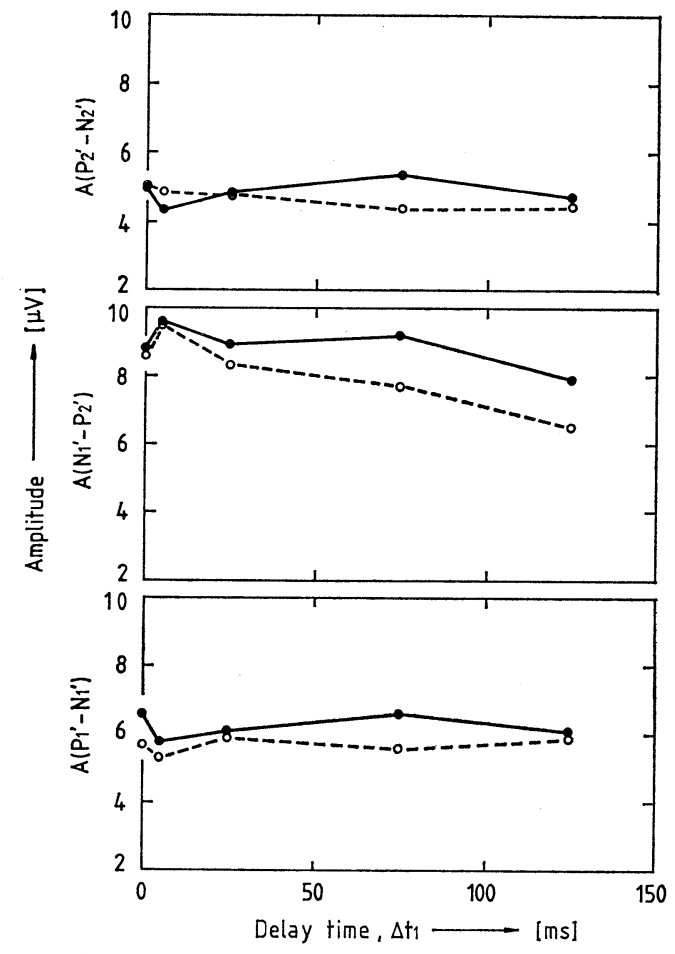

(b)

Fig. 3 Averaged amplitudes of AEPs over the left and right hemispheres (8 subjects). Left hemisphere, ----: Right hemisphere. (a) Amplitudes as a function of the delay time $\Delta t_{1}$ of the sound field under test. (b) Amplitudes for the reference sound field with $\Delta t_{1}=$ $0 \mathrm{~ms}$.

with delay time and the reference sound field with $\Delta t_{1}$ $=0 \mathrm{~ms}$, respectively. The amplitudes show significant differences according to (1) the delay time $\Delta t_{1}\left[\left(A\left(\mathrm{P}_{1-}\right.\right.\right.$ $\left.\mathrm{N}_{1}\right): p<0.01, A\left(\mathrm{~N}_{1}-\mathrm{P}_{2}\right): p<0.01$, and $A\left(\mathrm{~N}_{1}{ }^{\prime}-\mathrm{P}_{2}{ }^{\prime}\right)$ : $p<0.01)]$; (2) hemispheric differences $\left[A\left(\mathrm{P}_{1}-\mathrm{N}_{1}\right)\right.$ : $p<0.01, A\left(\mathrm{~N}_{1}-\mathrm{P}_{2}\right): p<0.05, A\left(\mathrm{P}_{1}{ }^{\prime}-\mathrm{N}_{1}{ }^{\prime}\right): p<0.05$, and $\left.\left.A\left(\mathrm{~N}_{1}{ }^{\prime}-\mathrm{P}_{2}{ }^{\prime}\right): p<0.01\right)\right]$; and (3) individual differences [ $p<0.01$ in all cases]. Figure 3 shows the changes of mean amplitudes in relation to the delay time $\Delta t_{1}$ of the test sound field as well as in reference to $\Delta t_{1}=$ 0 ms. Amplitudes $A\left(\mathbf{P}_{1}-\mathrm{N}_{1}\right), A\left(\mathrm{~N}_{1}-\mathbf{P}_{2}\right), A\left(\mathrm{P}_{1}{ }^{\prime}-\mathrm{N}_{1}{ }^{\prime}\right)$ and $A\left(\mathrm{~N}_{1}{ }^{\prime}-\mathrm{P}_{2}{ }^{\prime}\right)$ were significantly greater from the left hemisphere than from the right hemisphere for the entire range of delays, showing the left hemispheric dominance for the speech signal. It is found that amplitudes greatly change in a very short delay time range of $\Delta t_{1}<5 \mathrm{~ms}$, but there were no consistent changes in relation to delay time for $5 \mathrm{~ms}<\Delta t_{1}<$ $125 \mathrm{~ms}$. Neither hemispheric differences nor stimulus effects for both $A\left(\mathbf{P}_{2}-\mathrm{N}_{2}\right)$ and $A\left(\mathbf{P}_{2}^{\prime}-\mathrm{N}_{2}{ }^{\prime}\right)$ were observed.

The latencies for the test sound fields are presented in Table 3. Analysis of variance showed no significant stimulus effects and hemispheric differences for the latency at the $P_{1}$ and $\mathbf{N}_{1}$ peaks. However, $\mathbf{P}_{2}, \mathbf{N}_{2}$ and $\mathbf{P}_{3}$ showed significant stimulus effects $\left(\mathrm{P}_{2}: p<\right.$ $0.01, \mathrm{~N}_{2}: p<0.01$, and $\mathrm{P}_{3}: p<0.01$ ). Plots of the data given in Table 3 appear in Fig. 4 (a), where changes of each latency are shown as a function of the delay time $\Delta t_{1}$. As shown in the figure, the latencies of the $P_{1}$ and $N_{1}$ peaks showed no systematic changes in relation to the delay time $\Delta t_{1}$. However it is quite remarkable that the latencies for the $\mathbf{P}_{2}, \mathbf{N}_{2}$, and $\mathbf{P}_{3}$ peaks have maximum values at $\Delta t_{1}=25 \mathrm{~ms}$. In contrast to amplitude responses, no hemispheric differences were observed for any of the peaks. The latencies of $\mathrm{N}_{2}$ and $\mathbf{P}_{3}$ appeared to be delayed parallel to the latency of $\mathbf{P}_{2}$. In particular, latency differ- 


\section{Y. ANDO et al.: AUDITORY-EVOKED POTENTIAL AND PREFERENCE}

Table 3 Means for each peak latency for the eight subjects, in milliseconds, as a function of delay time $\Delta t_{1}$ of the test sound. Values in brackets show standard deviation.

\begin{tabular}{|c|c|c|c|c|c|c|c|c|c|c|}
\hline \multirow{3}{*}{ Peak } & \multicolumn{5}{|c|}{ Left hemisphere } & \multicolumn{5}{|c|}{ Right hemisphere } \\
\hline & \multicolumn{5}{|c|}{ Delay time, $\Delta t_{1}[\mathrm{~ms}]$} & \multicolumn{5}{|c|}{ Delay time, $\Delta t_{1}[\mathrm{~ms}]$} \\
\hline & 0 & & 25 & & 125 & 0 & 5 & 25 & 75 & 125 \\
\hline$P_{1}$ & $\begin{array}{c}55 \\
(9.5)\end{array}$ & $\begin{array}{c}58 \\
(4.2)\end{array}$ & $\begin{array}{c}60 \\
(11.9)\end{array}$ & $\begin{array}{c}58 \\
(13.3)\end{array}$ & $\begin{array}{c}59 \\
(7.1)\end{array}$ & $\begin{array}{c}63 \\
(10.8)\end{array}$ & $\begin{array}{c}62 \\
(9.7)\end{array}$ & $\begin{array}{c}58 \\
(9.8)\end{array}$ & $\begin{array}{c}59 \\
(12.2)\end{array}$ & $\begin{array}{c}59 \\
(4.7)\end{array}$ \\
\hline $\mathrm{N}_{1}$ & $\begin{array}{c}108 \\
(7.9)\end{array}$ & $\begin{array}{c}108 \\
(10.5)\end{array}$ & $\begin{array}{l}117 \\
(9.4)\end{array}$ & $\begin{array}{c}115 \\
(14.0)\end{array}$ & $\begin{array}{c}108 \\
(8.7)\end{array}$ & $\begin{array}{c}114 \\
(10.0)\end{array}$ & $\begin{array}{c}111 \\
(11.1)\end{array}$ & $\begin{array}{c}113 \\
(16.8)\end{array}$ & $\begin{array}{c}111 \\
(12.9)\end{array}$ & $\begin{array}{c}106 \\
(11.1)\end{array}$ \\
\hline $\mathbf{P}_{2}$ & $\begin{array}{c}186 \\
(11.8)\end{array}$ & $\begin{array}{c}213 \\
(17.1)\end{array}$ & $\begin{array}{c}216 \\
(28.4)\end{array}$ & $\begin{array}{c}191 \\
(21.2)\end{array}$ & $\begin{array}{c}182 \\
(16.3)\end{array}$ & $\begin{array}{c}188 \\
(12.1)\end{array}$ & $\begin{array}{l}209 \\
(9.8)\end{array}$ & $\begin{array}{c}214 \\
(30.5)\end{array}$ & $\begin{array}{c}192 \\
(18.0)\end{array}$ & $\begin{array}{c}181 \\
(16.4)\end{array}$ \\
\hline $\mathrm{N}_{2}$ & $\begin{array}{c}251 \\
(16.4)\end{array}$ & $\begin{array}{c}264 \\
(24.2)\end{array}$ & $\begin{array}{c}273 \\
(23.3)\end{array}$ & $\begin{array}{c}247 \\
(27.0)\end{array}$ & $\begin{array}{c}242 \\
(16.0)\end{array}$ & $\begin{array}{c}246 \\
(26.0)\end{array}$ & $\begin{array}{c}270 \\
(24.4)\end{array}$ & $\begin{array}{c}270 \\
(25.5)\end{array}$ & $\begin{array}{c}247 \\
(31.1)\end{array}$ & $\begin{array}{c}243 \\
(26.4)\end{array}$ \\
\hline $\mathbf{P}_{3}$ & $\begin{array}{c}285 \\
(18.9)\end{array}$ & $\begin{array}{c}296 \\
(28.2)\end{array}$ & $\begin{array}{c}308 \\
(30.0)\end{array}$ & $\begin{array}{c}290 \\
(27.2)\end{array}$ & $\begin{array}{c}278 \\
(28.7)\end{array}$ & $\begin{array}{c}280 \\
(29.6)\end{array}$ & $\begin{array}{c}294 \\
(27.8)\end{array}$ & $\begin{array}{c}302 \\
(26.1)\end{array}$ & $\begin{array}{c}281 \\
(29.8)\end{array}$ & $\begin{array}{c}284 \\
(29.3)\end{array}$ \\
\hline
\end{tabular}

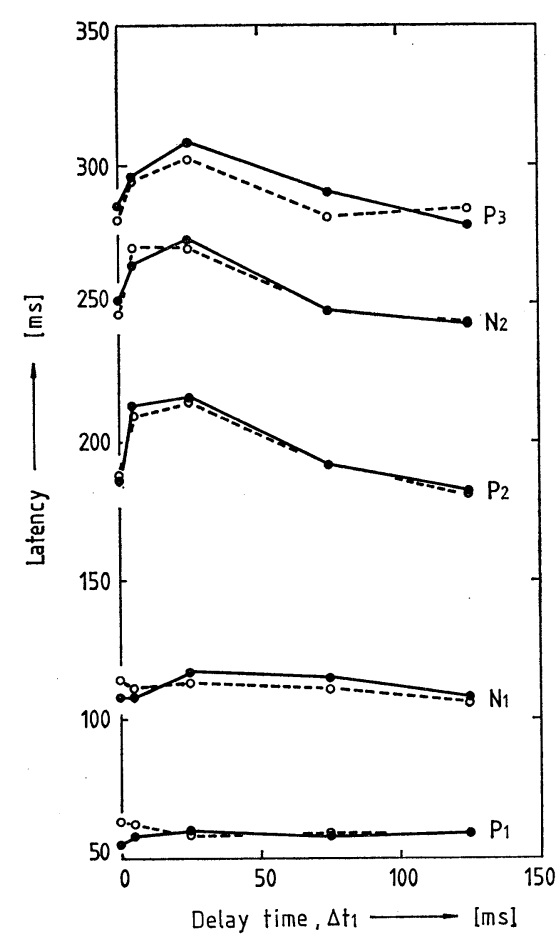

(a)

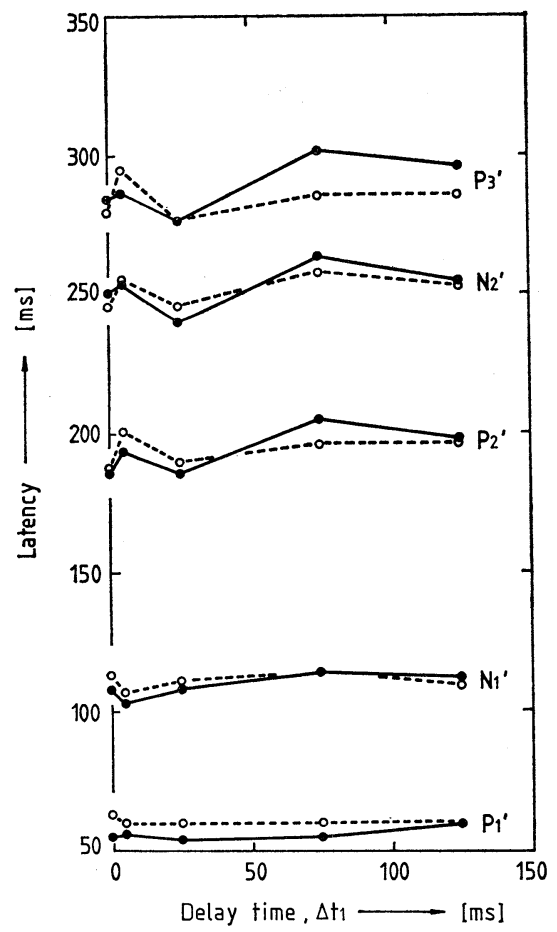

(b)

Fig. 4 Averaged latencies as a function of the delay time $\Delta t_{1}$ (8 subjects). - - : Left hemisphere, ---: Right hemisphere. (a) Latencies of the sound field under test. Maximum latencies of $\mathrm{P}_{2}, \mathrm{~N}_{2}$, and $\mathrm{P}_{3}$ are found at $\Delta t_{1}=25 \mathrm{~ms}$. (b) Latencies of the reference sound field $\left(\Delta t_{1}=0 \mathrm{~ms}\right)$. Relatively short latencies of $\mathrm{P}_{2}{ }^{\prime}, \mathrm{N}_{2}{ }^{\prime}$, and $\mathrm{P}_{3}{ }^{\prime}$ are found at $\Delta t_{1}=25 \mathrm{~ms}$, on the contrary.

ences except for $\mathrm{N}_{1}-\mathrm{P}_{2}$ appeared to be nearly constant for the delay time $\Delta t_{1}$, and the maximum value of latency difference for $\mathrm{N}_{1}-\mathrm{P}_{2}$ was only observed at $\Delta t_{1}=25 \mathrm{~ms}$. These suggest that the change of latency according to the delay time occurs only at $\mathbf{P}_{2}$. Since sound stimuli with and without delays were 
Table 4 Means for each peak latency for the eight subjects, in milliseconds, as a function of delay time $\Delta t_{1}$ of the paired test sound for the reference sound with $\Delta t_{1}=0 \mathrm{~ms}$. Values in brackets show standard deviation.

\begin{tabular}{|c|c|c|c|c|c|c|c|c|c|c|}
\hline \multirow{3}{*}{ Peak } & \multicolumn{5}{|c|}{ Left hemisphere } & \multicolumn{5}{|c|}{ Right hemisphere } \\
\hline & \multicolumn{5}{|c|}{ Delay time, $\Delta t_{1}[\mathrm{~ms}]$} & \multicolumn{5}{|c|}{ Delay time, $\Delta t_{1}[\mathrm{~ms}]$} \\
\hline & 0 & 5 & 25 & 75 & 125 & 0 & 5 & 25 & 75 & 125 \\
\hline$P_{1}^{\prime}$ & $\begin{array}{c}55 \\
(9.5)\end{array}$ & $\begin{array}{r}56 \\
(12.7)\end{array}$ & $\begin{array}{c}54 \\
(11.3)\end{array}$ & $\begin{array}{c}55 \\
(14.0)\end{array}$ & $\begin{array}{c}59 \\
(15.5)\end{array}$ & $\begin{array}{c}63 \\
(10.8)\end{array}$ & $(12.7)$ & $\begin{array}{c}60 \\
(9.6)\end{array}$ & $\begin{array}{c}60 \\
(12.1)\end{array}$ & $\begin{array}{c}60 \\
(10.9)\end{array}$ \\
\hline $\mathrm{N}_{1}^{\prime}$ & $\begin{array}{c}108 \\
(7.8)\end{array}$ & $\begin{array}{c}103 \\
(11.4)\end{array}$ & $\begin{array}{c}108 \\
(12.2)\end{array}$ & $\begin{array}{c}114 \\
(7.7)\end{array}$ & $\begin{array}{c}112 \\
(11.8)\end{array}$ & $\begin{array}{c}113 \\
(10.3)\end{array}$ & $\begin{array}{c}107 \\
(8.9)\end{array}$ & $\begin{array}{c}111 \\
(7.3)\end{array}$ & $\begin{array}{c}104 \\
(7.4)\end{array}$ & $\begin{array}{c}109 \\
(11.6)\end{array}$ \\
\hline $\mathbf{P}_{2}^{\prime}$ & $\begin{array}{c}186 \\
(11.9)\end{array}$ & $\begin{array}{c}194 \\
(14.2)\end{array}$ & $\begin{array}{c}186 \\
(14.1)\end{array}$ & $\begin{array}{c}205 \\
(21.6)\end{array}$ & $\begin{array}{c}198 \\
(15.2)\end{array}$ & $\begin{array}{c}188 \\
(12.1)\end{array}$ & $\begin{array}{c}201 \\
(22.2)\end{array}$ & $\begin{array}{c}190 \\
(19.1)\end{array}$ & $\begin{array}{c}196 \\
(18.6)\end{array}$ & $\begin{array}{c}196 \\
(14.9)\end{array}$ \\
\hline $\mathrm{N}_{2}^{\prime}$ & $\begin{array}{c}251 \\
(16.4)\end{array}$ & $\begin{array}{c}254 \\
(22.7)\end{array}$ & $\begin{array}{c}240 \\
(25.0)\end{array}$ & $\begin{array}{c}264 \\
(19.4)\end{array}$ & $\begin{array}{c}255 \\
(24.0)\end{array}$ & $\begin{array}{c}246 \\
(25.9)\end{array}$ & $\begin{array}{c}256 \\
(46.0)\end{array}$ & $\begin{array}{c}246 \\
(26.9)\end{array}$ & $\begin{array}{c}258 \\
(19.7)\end{array}$ & $\begin{array}{c}253 \\
(28.5)\end{array}$ \\
\hline $\mathbf{P}_{3}^{\prime}$ & $\begin{array}{c}285 \\
(18.9)\end{array}$ & $\begin{array}{c}287 \\
(21.1)\end{array}$ & $\begin{array}{c}277 \\
(24.1)\end{array}$ & $\begin{array}{c}302 \\
(30.9)\end{array}$ & $\begin{array}{c}292 \\
(29.6)\end{array}$ & $\begin{array}{c}280 \\
(29.6)\end{array}$ & $\begin{array}{c}295 \\
(26.7)\end{array}$ & $\begin{array}{c}277 \\
(25.8)\end{array}$ & $\begin{array}{c}286 \\
(26.4)\end{array}$ & $\begin{array}{c}286 \\
(35.1)\end{array}$ \\
\hline
\end{tabular}

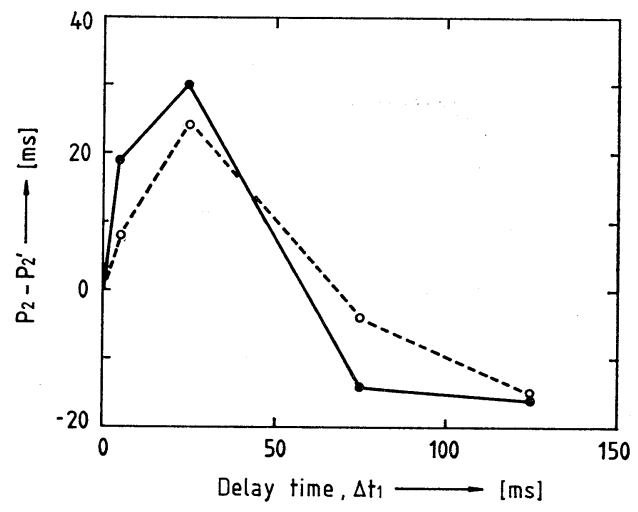

Fig. 5 Latency difference, $\mathrm{P}_{2}-\mathrm{P}_{2}{ }^{\prime}$, due to presentation of two sound fields alternately, as a function of $\Delta t_{1}$. - : Left hemisphere, ----: Right hemisphere.

alternately given, it is interesting to know whether or not the AEP in response to the reference sound field without delay $\left(\Delta t_{1}=0 \mathrm{~ms}\right)$ would relatively vary according to the paired test sound field. Table 4 and Fig. 4 (b) show changes in latency for AEPs of the reference sound field without delay as a function of the delay time of the paired test sound field $\left[\mathbf{P}_{2}{ }^{\prime}\right.$ $(p<0.05), \mathrm{N}_{2}{ }^{\prime}(p<0.05)$, and $\left.\mathrm{P}_{3}{ }^{\prime}(p<0.01)\right]$. When the delay of the test sound field was $25 \mathrm{~ms}$, a relatively short latency for $\mathbf{P}_{2}{ }^{\prime}, \mathbf{N}_{2}{ }^{\prime}$, and $\mathbf{P}_{3}{ }^{\prime}$ was observed in the reference sound field.

In Fig. 5, the latency difference between two sound fields, $\mathbf{P}_{2}-\mathbf{P}_{2}^{\prime}$ (latency difference), from both hemispheres is shown as a function of the delay time. It is clear that the maximum value of $\mathbf{P}_{2}-\mathbf{P}_{2}{ }^{\prime}$ occurred at $\Delta t_{1}=25 \mathrm{~ms}$. This curve as a relative response will be discussed in relation to the scale values of preference with respect to the delay time in the next section which is obtained from the paired comparison tests.

\section{TEST OF SUBJECTIVE PREFERENCE FOR SOUND FIELD WITH SINGLE REFLECTION}

After the AEP recording without asking for any subjective judgment, a paired comparison test was carried out, varying the delay time $\Delta t_{1}$ in order to confirm the degree of preference and to know a relationship between AEPs and preference.

\subsection{Procedure}

Similar to the AEP recording, two loudspeakers which produce direct frontal sound with single reflection were arranged at a distance of $1.2 \mathrm{~m}$ in the soundproof chamber. The delay of single reflection $\left(A_{1}=1.0\right)$ was adjusted from 0 to $125 \mathrm{~ms}$ (5 different delays), covering (1) only the direct sound $\left(\Delta t_{1}=0\right.$ $\mathrm{ms})$, (2) the coherent time region $\left(\Delta t_{1}=5 \mathrm{~ms}\right),(3)$ the most preferred region $\left(\Delta t_{1}=25 \mathrm{~ms}\right)$, and (4) the echo-disturbance-effect regions $\left(\Delta t_{1}=75 \mathrm{~ms}\right.$ and 125 $\mathrm{ms})$. The number of pairs was therefore ten in total. Since these loudspeakers were located in the median plane, the spatial parameter was held constant, i.e., IACC $\simeq 0.99$. The total pressure of the sound field at the listener's position was $77 \mathrm{dBA}$ (slow) at the peak level. 


\section{Y. ANDO et al.: AUDITORY-EVOKED POTENTIAL AND PREFERENCE}

The sound field pairs were presented to the same eight subjects in random order. They were required to judge which of the two sound fields they preferred to hear.

\subsection{Results}

With the probabilities obtained by the paired comparison tests, the scale value of preference was found by Thurstone's case $V .{ }^{10}$ ) The test of goodness of fit for the data obtained by the case $\mathrm{V}$ model showed that our observed data were satisfactory $(5 \%$ significance level). ${ }^{11)}$ The resulting scale value of preference is shown in Fig. 6 as a function of the delay time $\Delta t_{1}$. The most preferred delay time found is $25 \mathrm{~ms}$.

The preferred delay time $\left[\Delta t_{1}\right]_{\mathrm{p}}$ can be calculated in a similar way, as in previous reports. ${ }^{3-5)}$

$$
\left[\Delta t_{1}\right]_{\mathrm{p}}=\tau_{\mathrm{p}}
$$

such that

$$
\left|\phi_{\mathrm{p}}(\tau)\right|_{\text {envelope }} \simeq k A^{c} \text { at } \tau<\tau_{\mathrm{p}},
$$

where $\phi_{\mathrm{p}}(\tau)$ is the normalized ACF of source signals, $k=$ const. (0.1), $c=$ const. (1.0), and

$$
A=\left\{\sum_{n=1}^{\infty} A_{n}{ }^{2}\right\}^{1 / 2} .
$$

In this study $A=A_{1}=1.0$; thus the most preferred delay time corresponds well to the effective duration of ACF, i.e., $\tau_{\mathrm{e}}=25 \mathrm{~ms}$ (Fig. 1), reconfirming the previous study.

Figure 7 plots the scale value of preference versus the latency $\mathbf{P}_{2}$ and latency difference $\mathbf{P}_{2}-\mathbf{P}_{2}{ }^{\prime}$. The correlation coefficient between preference and $\mathrm{P}_{2}$ is 0.76 (at $5 \%$ significance level), and the correlation coefficient between preference and $\mathbf{P}_{2}-\mathbf{P}_{2}{ }^{\prime}$ is 0.88 (at $1 \%$ significance level). The relations shown in the figure indicate that the latency difference of AEP relate much more closely to the preference value of the sound field than the latency of $\mathbf{P}_{2}$ for the test sound field only.

\section{DISCUSSION}

The information which distinguishes between the left and right hemispheres in the electrophysiological response to speech stimuli may be basically reflected by the amplitude components, in particular at amplitude $A\left(\mathrm{P}_{1}-\mathrm{N}_{1}\right)$. This result can be interpreted to confirm previous reports on the asymmetry of hemispheric functions in the speech-processing mechanism. ${ }^{12-14)}$ It is considered that the amplitude com-

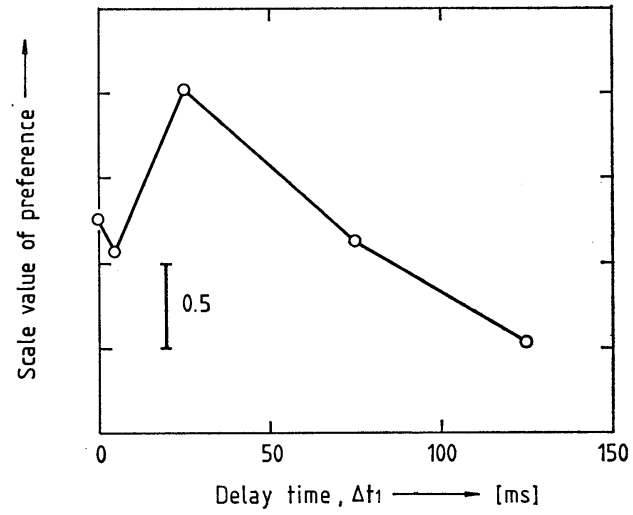

Fig. 6 Scale value of preference as a function of the delay time $\Delta t_{1}$ ( 8 subjects: the same subjects as for AEP recording).

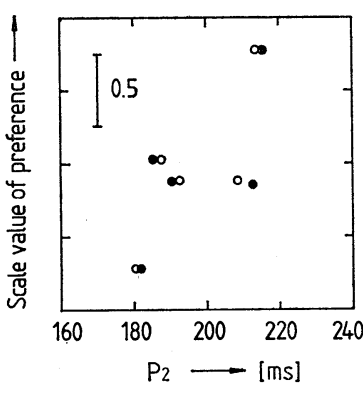

(a)

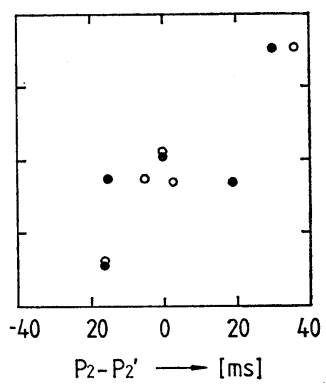

(b)
Fig. 7 Relationship between the scale value of preference and latency of $P_{2}$ and latency difference $\mathrm{P}_{2}-\mathrm{P}_{2}{ }^{\prime}$. $\bullet$ : Left hemisphere, $\bigcirc$ : Right hemisphere. (a) Scale value and latency of $\mathrm{P}_{2}$ (correlation coefficient $=0.76$ at $5 \%$ significance level), (b) Scale value and latency difference, $\mathbf{P}_{2}-\mathbf{P}_{2}{ }^{\prime}$ (correlation coefficient $=0.88$ at $1 \%$ significance level).

ponents of the AEP relate most closely to the physical parameters of the stimuli (for example, speech or noise) indicating hemispheric differences, while the latency components relate most closely to psychological parameters (i.e., subjective preference in this study).

The comparison of subjective responses and AEPs for both hemispheres revealed that the latency change of the $\mathrm{P}_{2}$ peak due to the delay shows the maximum value at $\Delta t_{1}=25 \mathrm{~ms}$, which coincides with the most preferred delay time. The $\mathrm{P}_{2}$ latency roughly increases with subjective preference. The change of 
evoked potentials related to the perception of a single delay seems to appear at later responses of AEPs, in particular in latency components (approximately $200 \mathrm{~ms}$ ) rather than amplitude components. The observation of relatively long latency at the most preferred delay $\left(\Delta t_{1}=25 \mathrm{~ms}\right)$ may be interpreted as relaxation of the subjects and/or sensation of pleasure.

The preferred initial delay time is found to be identical with the time delay at which the envelope of the normalized ACF becomes $0.1\left(A_{1}=1.0\right)$. This result confirms those of previous investigations of musical and speech sound field with single reflection. ${ }^{3,4)}$ Subjective responses of the sound field were divided into three regions according to the autocorrelation mechanism ${ }^{1}$ : (1) tone coloration region, (2) the most preferred region, and (3) echo disturbance region. It is considered that the subjective coloration and the echo disturbance effects may be associated with the short latency as an unpleasant response; on the other hand, the longest latency corresponds to the most preferred region.

The changes of evoked responses to a reference stimulus $\left(\Delta t_{1}=0 \mathrm{~ms}\right)$ due to the paired test sound field showed, on the contrary, that relatively short latency for $\mathbf{P}_{2}{ }^{\prime}$ is observed when the delay of the test sound field is $25 \mathrm{~ms}$, which was the most preferred delay time. It is quite remarkable that the relative response in latency between a pair of sound fields, $\mathbf{P}_{2}-\mathbf{P}_{2}{ }^{\prime}$, corresponds more clearly to the preference values than the latency of $\mathbf{P}_{2}$ only (see Fig. 7). As far as the monaural criterion (for example, initial delay time) is concerned, therefore, this suggests that the brain activity associated with preference judgment for a pair of sound fields can be explained on the basis of relative brain processes. This relation also suggests the use of the latency difference of AEP for a pair of sound fields to predict objectively the preference value of the sound field only by the measurement of AEPs.

A similar phenomenon has been found in another experiment, in which the effect of subjective diffuseness of sound fields on AEPs was investigated. Results showed that the latency of the later stage of AEPs increased as IACC decreased. ${ }^{15)}$ We should note that the scale value of subjective diffuseness and/or preference increases with decreasing IACC.

\section{ACKNOWLEDGMENTS}

The authors would like to thank to Prof. Z. Maekawa and Dr. S. Shirataki for discussions and to Mr. S. Osaki and Mr. H. Nagamatsu for their cooperation. Also, we thank the subjects who participated during the experimental sessions.

\section{REFERENCES}

1) Y. Ando, Concert Hall Acoustics (Springer-Verlag, Berlin, Heidelberg, New York, Tokyo, 1985), pp. 48-88.

2) Y. Ando, "Calculation of subjective preference at each seat in a concert hall," J. Acoust. Soc. Am. 74, 873-887 (1983).

3) Y. Ando, "Subjective preference in relation to objective parameter of music sound fields with a single echo," J. Acoust. Soc. Am. 62, 1436-1442 (1977).

4) Y. Ando and K. Kageyama, "Subjective preference of sound with a single early reflection," Acustica 37, 111-117 (1977).

5) Y. Ando and M. Imamura, "Subjective preference tests for sound fields in concert halls simulated by the aid of a computer," J. Sound Vib. 65, 229-239 (1979).

6) Y. Ando and D. Gottlob, "Effects of early multiple reflections on subjective preference judgments of music sound field," J. Acoust. Soc. Am. 65, 524 527 (1979).

7) S. H. Kang and Y. Ando, "Comparison between subjective preference judgments for sound fields by different nations," Mem. Grad. Sch. Sci. Technol., Kobe Univ. 3-A, 71-76 (1985).

8) G. G. Briggs and R. D. Nebes, "Patterns of hand preference in a student population," Cortex $\mathbf{6 2}$, 720-737 (1977).

9) H. H. Jasper, "The ten-twenty electrode system of the international federation," Electroencephalogr. Clin. Neurophysiol. 10, 371-375 (1958).

10) L. L. Thurstone, "A law of comparative judgment," Psychol. Rev. 34, 273-289 (1927).

11) F. Mosteller, "Remarks on the method of paired comparisons III," Psychometrica 16, 207-218 (1951).

12) R. Chon, "Differential cerebral processing of noise and verbal stimuli," Science 172, 599-601 (1971).

13) N. Neville, "Electrographic correlates of lateral asymmetry of verbal and nonverbal auditory stimuli," J. Psycholinguist. Res. 3, 151-163 (1974).

14) L. K. Morrell and J. G. Salamy, "Hemispheric asymmetry of electrocortical responses to speech stimuli," Science 174, 164-166 (1972).

15) Y. Ando, S. H. Kang, and H. Nagamatsu, "On the auditory-evoked potential in relation to the IACC of sound field," J. Acoust. Soc. Jpn. (E) 8, 183-190 (1987). 